\title{
Life cycle human health impacts of 875 pesticides
}

\author{
Fantke, Peter; Jolliet, Oliver
}

Published in:

International Journal of Life Cycle Assessment

Link to article, DOI:

10.1007/s11367-015-0910-y

Publication date:

2016

Document Version

Peer reviewed version

Link back to DTU Orbit

Citation (APA):

Fantke, P., \& Jolliet, O. (2016). Life cycle human health impacts of 875 pesticides. International Journal of Life Cycle Assessment, 21(5), [722-733]. https://doi.org/10.1007/s11367-015-0910-y

\section{General rights}

Copyright and moral rights for the publications made accessible in the public portal are retained by the authors and/or other copyright owners and it is a condition of accessing publications that users recognise and abide by the legal requirements associated with these rights.

- Users may download and print one copy of any publication from the public portal for the purpose of private study or research.

- You may not further distribute the material or use it for any profit-making activity or commercial gain

- You may freely distribute the URL identifying the publication in the public portal

If you believe that this document breaches copyright please contact us providing details, and we will remove access to the work immediately and investigate your claim. 


\section{$1 \quad$ Life cycle human health impacts of 875 pesticides}

2 Peter Fantke $\mathrm{e}^{\mathrm{a}, *}$, Olivier Jolliet ${ }^{\mathrm{b}, \mathrm{c}}$

3

$4{ }^{a}$ Quantitative Sustainability Assessment Division, Department of Management Engineering,

5 Technical University of Denmark, Produktionstorvet 424, 2800 Kgs. Lyngby, Denmark

$6 \quad{ }^{b}$ Environmental Health Sciences, School of Public Health, University of Michigan, Ann

7 Arbor, MI 48109, USA

$8 \quad{ }^{\mathrm{c}}$ Quantis, EPFL Science Park (PSE-D), CH-1015 Lausanne, Switzerland

9

10 *Corresponding author: Tel.: +45 45254452, fax: +45 45933435. E-mail: pefan@ dtu.dk 


\section{Abstract}

Purpose Residues in field crops grown and harvested for human consumption are the main contributor to overall human exposure toward agricultural pesticides for the general population. However, exposure from crop residues is currently not considered in life cycle assessment practice. We therefore present a consistent framework for characterizing human toxicological impacts associated with pesticides applied to agricultural crops in the frame of life cycle impact assessment based on state-of-the-art data and methods.

Methods We combine a dynamic multicrop plant uptake model designed for evaluating human exposure to residues for a wide range of pesticide-crop combinations with latest findings of pesticide dissipation kinetics in crops and post-harvest food processing. Outcome is a set of intake fractions and characterization factors for 875 organic pesticides and 6 major food crops along with specific confidence intervals for each factor.

Results and Discussion Intake fractions aggregating exposure via crop residues and exposure via fractions lost to air and soil for pesticides applied to agricultural crops vary between $10^{-8}$ and $10^{-1} \mathrm{~kg}$ intake per $\mathrm{kg}$ applied as a function of pesticide and crop. Intake fractions are typically highest for lettuce and tomato and lowest for potato due to differences in application times before crop harvest and soil as additional barrier for uptake into potato tubers. Uncertainty in intake fractions is mainly associated with dissipation dynamics in crops, where results demonstrate that using pesticide- and crop-specific data is crucial. Combined with the uncertainty in effect modeling, characterization factors per pesticide and crop show squared geometric mean standard deviations ranging from 38 to 15560 over a variability range across pesticide-crop combinations of 10 orders of magnitude.

Conclusions Our framework is operational for use in current life cycle impact assessment models, is made available for USEtox, and closes an important gap in the assessment of human exposure to pesticides. For ready use in life cycle assessment studies, we present pesticide-crop combination-specific characterization factors normalized to pesticide mass 
37 applied and provide default data for application times and loss due to post-harvest food 38 processing. When using our data, we emphasize the need to consult current pesticide 39 regulation, since each pesticide is registered for use on certain crops only, which varies 40 between countries.

41

42 Keywords: dynamiCROP plant uptake model; human toxicity characterization factors;

43 pesticides; life cycle impact assessment (LCIA); food crop consumption; intake fractions 


\section{Introduction}

Food is an important source of human exposure to toxic chemicals which includes residues of pesticides, perfluorinated chemicals, metals, phthalates, and persistent organic pollutants including dioxins and polychlorinated biphenyls. Common sources of residues in food along food product life cycles are agricultural production and harvesting, food packaging, storage, industrial and domestic food processing, and finally serving (DicksonSpillmann et al. 2009, Freeman 2011, Lippmann 2009, Muncke 2009, Tittlemier et al. 2007). In this context, pesticides are a special chemical class of interest, because they are intentionally applied to agricultural field crops, they have by design toxic properties, and the general public in various countries is concerned about chronic effects from low-level exposure (European Commission 2006, McKinlay et al. 2008, Pretty 2005, Slovic 2010). For pesticides, food crop consumption is the predominant pathway for human exposure (Caldas \& Jardim 2012, Fantke et al. 2011a, Lu et al. 2008). Therefore, assessing pesticide residues in food crops is a key component in current pesticide authorization in Europe (European Commission 2009) and elsewhere and needs to be considered for assessing the environmental performance of food products over their life cycle.

Life cycle assessment (LCA) is a tool that is frequently applied to evaluate the environmental performance of agricultural production systems as well as various food products including crops (Andersson 2000, Perrin et al. 2014, Roy et al. 2009, Schau \& Fet 2008). However, although health impacts from environmental emissions associated with the use of pesticides in food crop production are considered in some agrifood-related LCA studies, human exposure to pesticide residues in the treated food crops is still mostly disregarded (Fantke et al. 2011b, Juraske \& Sanjuán 2011). This is mainly due to the fact that current tools for estimating pesticide residues in food crops show considerable uncertainties mostly associated with dissipation kinetics in crops (Fantke et al. 2012a, Juraske et al. 2008). Furthermore, these tools are not implemented in current life cycle impact assessment (LCIA) 
models and methods for assessing human health impacts from exposure to potentially toxic chemicals including pesticides. To address this gap, we propose to (a) develop an operational framework for consistently incorporating health impacts from exposure to residues in food crops associated with field applications of agricultural pesticides into LCIA. We further aim at reducing uncertainty of pesticide-related characterization factors by integrating the latest findings from Fantke and Juraske (2013) and Fantke et al. (2014) in estimating dissipation kinetics in crops to (b) calculate harvest fractions, intake fractions and characterization factors for 875 pesticides and to (c) estimate the resulting specific uncertainty for each of these factors.

\section{Methods}

The general framework applied in LCIA for characterizing human toxicological impacts associated with chemical emissions combines factors representing environmental fate, human exposure, and health endpoint-specific dose-response into characterization factors (European Commission 2010, Udo de Haes et al. 2002). At midpoint level, human toxicological characterization factors relate numbers of health incidences to emitted chemical mass. At endpoint level, characterization factors contain an additional term accounting for the (damage or health endpoint-specific) severity and are expressed in terms of disability-adjusted life years (DALY) per emitted chemical mass. Environmental fate and human exposure can be aggregated into the human intake fraction that directly relates the chemical mass taken in by an exposed (or the entire global) human population to the chemical mass emitted (Bennett et al. 2002). This general framework for assessing human toxicity impacts in LCIA under assumed steady-state conditions was originally designed to be applied for environmental emissions, i.e. related characterization factors are normalized to a unit mass continuously released into a specific environmental compartment, such as air, water, or soil (Rosenbaum et al. 2008). However, pesticides are not emitted continuously, but are rather applied as pulses to 
agricultural crops that are harvested within days to weeks after the (latest) application.

Steady-state might, hence, often not be reached, especially when pesticides are applied shortly before crop harvest (Fantke et al. 2013, Rein et al. 2011). In addition, the fraction of the applied pesticide mass that is intercepted by the crop surface and that ends up as residues in crop harvest along with the fractions that are lost during and after the application and that reach target field and off-target soil, air and water including surface and groundwater are not typically reported or available for LCA practitioners (Perrin et al. 2014). Instead, in most cases the applied pesticide mass or mass per area is available, from which fractions reaching the treated crop and fractions reaching the environment as emissions then need to be estimated (Rosenbaum et al. 2015). Consequently, the current framework applied for human toxicity assessment of chemicals in LCIA needs to be extended and modified as detailed in the following to reflect the mass distribution dynamics between pesticide application and food crop harvest.

\subsection{Modeling framework for pesticide exposure}

Characterization factors: Our starting point is the multicrop model for characterizing health impacts from pesticide residues in food crops, dynamiCROP, that describes the mass evolution of pesticides in different crop-environment systems based on solving a set of coupled differential equations. This model is fully described in Fantke et al. (2011a) and Fantke et al. (2011b) and is designed for evaluating human toxicological impacts associated with pesticide residues in wheat, paddy rice, apple, tomato, potato and lettuce, representing the most relevant crop archetypes with respect to human vegetal food consumption.

Following this approach, human toxicity characterization factors, $\mathrm{CF}_{x, t, e}$ [incidences $\mathrm{kg}_{\text {applied }}^{-1}$ at midpoint level, DALY $\mathrm{kg}_{\text {applied }}^{-1}$ at endpoint level], for pesticides applied to crop $x$ harvested at time $t$ [days after application] associated with health endpoints $e$ are calculated from 
121 toxicity effect factors for aggregated cancer and non-cancer health effects, $\mathrm{EF}_{e}$

122 [incidences $\mathrm{kg}_{\text {intake }}^{-1}$ at midpoint level, DALY $\mathrm{kg}_{\text {intake }}^{-1}$ at endpoint level] and

123 human intake fractions, $\mathrm{iF}_{x, t}\left[\mathrm{~kg}_{\text {intake }} \mathrm{kg}_{\text {applied }}^{-1}\right]$, as

$124 \mathrm{CF}_{x, t, e}=\mathrm{EF}_{e} \times \mathrm{iF}_{x, t}$

Effect factors: Effect factors are derived as

126

$\mathrm{EF}_{e}= \begin{cases}\mathrm{DRF}_{e} & \Rightarrow \text { midpoint level } \\ \mathrm{DRF}_{e} \times \mathrm{SF}_{e} & \Rightarrow \text { endpoint level }\end{cases}$

127 with $\mathrm{DRF}_{e}$ [incidences $\mathrm{kg}_{\text {intake }}^{-1}$ ] as dose-response slope factor and $\mathrm{SF}_{e}$ [DALY incidence ${ }^{-1}$ ] as

128 damage or severity factor. Dose-response slope factors relate risks of humans to potentially

129 develop a health effect from pesticide exposure to the quantity inhaled or ingested and are

130 mainly taken from Rosenbaum et al. (2008). In case of missing data, $\mathrm{DRF}_{e}$ are extrapolated

131 from chronic lifetime doses affecting $50 \%$ of exposed humans or - if chronic data are not

132 available as for most non-cancer effects - from no-observed effect levels of exposed animal

133 species assuming linear dose-response relationships (Huijbregts et al. 2005, Kramer et al.

134 1996). The difference in the units of the effect factors (Eq. 2) and consequently of the

135 characterization factors is related to the fact that at midpoint level, the effect factor is solely

136 derived from (and therefore equal to) the dose-response slope factor, whereas at endpoint

137 level, a severity factor is included accounting for differences in effect severity. Severity

138 factors of 11.5 and 2.7 DALY incidence ${ }^{-1}$ are applied for cancer and non-cancer effects,

139 respectively (Huijbregts et al. 2005), to be used for comparative purposes rather than for

140 estimating absolute damages. Disability-adjusted life years are undiscounted and without age-

141 weighting.

142 Human intake fractions: To account for both the pesticide mass fraction reaching the crop

143 as residues and the fractions lost as emissions to air and soil during and after application,

144 human intake fractions relate the mass that is ultimately taken in by humans via all exposure 
145 pathways to the mass of applied pesticide. Hence, the total intake fraction per mass applied

146 combines the specific intake fractions for exposure to crop residues from the applied mass

147 reaching the treated crop with intake fractions for different exposure pathways $p$ including

148 inhalation and ingestion of drinking water and different food items from the applied mass

149 reaching air and soil:

150

$\mathrm{iF}_{x, t}=\mathrm{iF}_{x, t}^{\text {residues }}+f r_{x}^{\text {air }} \times \sum_{p} \mathrm{iF}_{p}^{\text {air }}+f r_{x}^{\text {soil }} \times \sum_{p} \mathrm{iF}_{p}^{\text {soil }}$

151 where $\mathrm{iF}_{x, t}^{\text {residues }}\left[\mathrm{kg}_{\text {intake }} \mathrm{kg}_{\text {applied }}^{-1}\right]$ is the intake fraction associated with exposure to residues in

152 the treated crop at harvest time based on a mechanistic plant uptake model accounting for

153 partitioning, transport and dissipation kinetics (see Section 2.2), $\mathrm{iF}_{p}^{\text {air }}\left[\mathrm{kg}_{\text {intake }} \mathrm{kg}_{\text {emitted to air }}^{-1}\right]$ is

154 the exposure pathway-specific intake fraction related to the fraction lost to air via e.g. wind

155 drift, $f r_{x}^{\text {air }}\left[\mathrm{kg}_{\text {emitted to air }} \mathrm{kg}_{\text {applied }}^{-1}\right]$, and $\mathrm{iF}_{p}^{\text {soil }}\left[\mathrm{kg}_{\text {intake }} \mathrm{kg}_{\text {emitted to soil }}^{-1}\right]$ is the exposure pathway-

156 specific intake fraction related to the fraction lost to soil via e.g. deposition, $f r_{x}^{\text {soil }}$

$157\left[\mathrm{~kg}_{\text {emitted to soil }} \mathrm{kg}_{\text {applied }}^{-1}\right]$. Intake fractions referring to mass emitted to air (beyond treated field

158 boundaries) and to soil (considering run-off and leaching to freshwater and disregarding direct

159 crop uptake as already considered in the intake fractions related to crop residues) are

160 calculated with USEtox (Rosenbaum et al. 2008) assuming continuous emissions and steady-

161 state conditions. Related fractions lost (emitted) to air during and after pesticide application

162 are assumed to be pesticide-generic, but crop-specific for a typical foliar application and

163 range from $5 \%$ for lettuce, $14.8 \%$ for potato, and $16.5 \%$ for wheat and paddy rice to $23.7 \%$

164 for tomato and 35.4\% for apple (Ganzelmeier et al. 1995, Rautmann et al. 2001, van de Zande

165 et al. 2007). We thereby acknowledge that different application techniques, such as aerial or

166 soil application would yield different fractions lost to air. Fractions lost to soil range from 2.3

167 to $81 \%$ assuming foliar application and are a function of pesticide properties (e.g. molecular

168 weight influencing deposition velocities), application time (where we distinguish per crop 
between averages for herbicides and other pesticides), and crop characteristics (e.g. growth stage and interception area influencing intercepted pesticide mass).

Intake fractions for crop residues are calculated from harvest fractions representing the

175 a food processing factor, $\mathrm{PF}_{x}\left[\mathrm{~kg}_{\text {intake }} \mathrm{kg}_{\text {in harvest }}^{-1}\right]$, accounting for post-harvest reduction of crop

176 residues due to subsequent food processing steps:

$\mathrm{iF}_{x, t}^{\text {residues }}=\mathrm{PF}_{x} \times \mathrm{hF}_{x, t}$

178 Since data are only available for a limited number of pesticide-crop combinations, pesticidegeneric food processing factors are applied as proxies, i.e. $0.59 \mathrm{~kg}_{\text {intake }} \mathrm{kg}_{\text {in harvest }}^{-1}$ for washing with tap water, $0.31 \mathrm{~kg}_{\text {intake }} \mathrm{kg}_{\text {in harvest }}^{-1}$ for parboiling or cooking, and $0.33 \mathrm{~kg}_{\text {intake }} \mathrm{kg}_{\text {in harvest }}^{-1}$ for bread making (Kaushik et al. 2009, Keikotlhaile et al. 2010, Liang et al. 2014). components $c, m_{x, c, t}^{\text {residues }}\left[\mathrm{kg}_{\text {in harvestedcropcomponent }}\right]$, and the sum of applied pesticide mass, $m_{x}^{\text {applied }}$

$\left[\mathrm{kg}_{\text {applied }}\right]$, and background mass, $m_{x}^{\text {background }}\left[\mathrm{kg}_{\text {in crop-environmert system }}\right]$ :

$\mathrm{hF}_{x, t}=\frac{\sum_{c} m_{x, c, t}^{\text {residues }}}{m_{x}^{\text {applied }}+m_{x}^{\text {background }}} \approx \frac{\sum_{c} m_{x, c, t}^{\text {residues }}}{m_{x}^{\text {applied }}}$

Both the pesticide mass applied directly to the treated crop and the soil residues from deposition or from earlier applications (background mass) that are taken up into the crop via the root system need to be considered according to Eq. 5. However, following the FAO recommendations for good agricultural practices for pesticide application (FAO 2003) as best

190 estimate in LCIA, we assume that the background pesticide input via root uptake from 191 previous applications and/or cross-field wind drift and subsequent deposition onto soil are 
192 negligible, i.e. we assume $m_{x}^{\text {background }} \approx 0 \mathrm{~kg}$. We justify this assumption with the fact that even

193 when applied in relatively quick succession to the same crop, previous studies have

194 demonstrated that typically only the latest direct application is dominating overall residues in crop harvest (Juraske et al. 2011, Rein et al. 2011). Hence, harvest fractions and all subsequent metrics, i.e. intake fractions and characterization factors, are normalized to the

197 (latest) pesticide mass applied to the respective crop, $m_{x}^{\text {applied }}$.

To obtain harvest fractions, we have solved the dynamics of a mass balance system of environmental compartments including air, soil and paddy water (the latter only for paddy rice) and crop components including root, stem, leaves, leaf surface, fruit and fruit surface (the latter two for all crops but lettuce and potato), which are all coupled by intercompartment transfers (Fantke et al. 2011a, Rein et al. 2011). Crop residues and resulting harvest fractions were found to be highly dependent on degradation in crops and time to harvest (Fantke et al. 2012b). From comparing modeled crop residues with measured data, we found that predicted residual masses over time were in good agreement with measured residues with $\mathrm{R}^{2}$ between 0.81 and 0.99 (Fantke et al. 2011a, Fantke et al. 2011b, Itoiz et al. 2012, Juraske et al. 2012). Since most input parameters that are required for solving the underlying mass balance system are typically not available to LCA practitioners and to be compatible with the format of assessment models and intake fractions applied in LCIA for 210 human toxicity assessment, the dynamiCROP model was linearized and a parametric 211 regression model was developed for each of the six crops still accounting for the main 212 influences on the dynamics between pesticide application and crop harvest (Fantke et al. 213 2012b, Fantke et al. 2013). Each model combines the contributions of different crop and 214 environmental components $c \in\{$ crop interior, crop surface, soil $\}$ at harvest time to the overall 215 residual pesticide mass found in crop harvest:

$216 \mathrm{hF}_{x, t}=\sum_{c} \mathrm{hF}_{x, c, t}=\sum_{c} 10^{\left(\alpha_{x, c}^{*}+\beta_{x, c} \times k_{x, c} \times t_{x}\right)}$ 
217 where $\alpha_{x, c}^{*}$ and $\beta_{x, c}$ denote dimensionless coefficients, $k_{x, c}\left[\mathrm{~kg}_{\text {reachingcomponent }}\right.$ day $^{-1}$ per

$218 \mathrm{~kg}_{\text {in component }}$, represent removal rate coefficients and $t_{x}$ [day] is the time between pesticide

219 application and crop harvest. Crop- and crop/environmental component-specific coefficients

$220 \alpha_{x, c}^{*}$ and $\beta_{x, c}$ are detailed in the Supporting Information (SI), Section S-1, and are adapted

221 from Fantke et al. (2012b). Removal rate coefficients for the soil component

$222 k_{x, c \in\{\text { soil }\}}=1 / \mathrm{FF}_{\text {soil }}$ are derived from the inverse of pesticide residence times in soil

223 corresponding to the fate factors for continental agricultural soil, $\mathrm{FF}_{\text {soil }}\left[\mathrm{kg}_{\text {in soil }}\right.$ per

$224 \mathrm{~kg}_{\text {emitted tosoil }} \mathrm{day}^{-1}$ ], in the USEtox matrix of fate factors (Rosenbaum et al. 2008). Removal

225 rate coefficients for crop interior and crop surface are generally obtained as

$226 k_{x, c \in\{\text { crop;crop-surface }\}}=\ln (2) / \mathrm{HL}_{x, c}^{\text {dissipation }}$ from overall removal (dissipation) half-lives $\mathrm{HL}_{x, c}^{\text {dissipation }}$

227 [day] estimated by Fantke et al. (2014) by fitting dissipation kinetics for 1485 distinct

228 pesticide-crop combinations reported in Fantke and Juraske (2013). For tomato, apple and

229 lettuce, additional terms contribute to $k_{x, c \in\{\text { crop;crop-surface }\}}$ accounting for the influence of

230 substance properties (see SI, Section S-1). Finally, crop-specific harvest times are taken from

231 Fantke et al. (2011b), Table S1, separately averaged for herbicides typically applied before or

232 during early crop stages and other pesticides, such as fungicides and insecticides, applied

233 during all crop stages including shortly before harvest and during post-harvest storage. With

234 these assumptions, we yield best estimates for crop residues and typically do not exceed

235 regulatory maximum residue limits (MRL) as demonstrated by Juraske et al. (2011), Juraske

236 et al. (2012), Itoiz et al. (2012), and Fantke et al. (2011a).

2.3 Uncertainty analysis

Uncertainty of harvest fractions, intake fractions and characterization factors (model

240 output) is expressed as $95 \%$ confidence interval ranges. Confidence intervals around model 
output $y$ are derived from a combination of uncertainty related to model input variables (input

242 parameter uncertainty) and uncertainty related to modeling of harvest fractions (regression

243 model uncertainty). Input parameter and model uncertainty are expressed as squared

244 geometric standard deviations $\mathrm{GSD}_{x_{i}}^{2}:=\exp \left(2 \times \sigma_{x_{i}}\right)$ with $\sigma_{x_{i}}>0$ the standard deviation of

245 the natural logarithm of input variable or regression model $x$ and the probability

$\left\{x_{i} / \mathrm{GSD}_{x_{i}}^{2}<x_{i}<\mathrm{GSD}_{x_{i}}^{2} \times x_{i}\right\}=0.95$ representing the $95 \%$ confidence interval around $x$ :

$\mathrm{GSD}_{y}^{2}=\exp \left(2 \times \sqrt{\sum_{i} \operatorname{var}\left(\ln \left(x_{i}\right)\right)}\right)=\exp \left(\sqrt{\sum_{i}\left(\ln \left(\mathrm{GSD}_{x_{i}}^{2}\right)\right)^{2}}\right)$

In Eq. 7, we use the fact that the variance of each input variable is related to the

corresponding $\mathrm{GSD}_{x_{i}}^{2}$ by $\operatorname{var}\left(\ln \left(x_{i}\right)\right)=\left(\ln \left(\mathrm{GSD}_{x_{i}}^{2}\right)\right)^{2}$. The choice of 2 in the exponent of the

250 geometric standard deviations reflects the rounded critical value from the Student's $t$ -

251 distribution. All input variables are mutually independent - see Fantke et al. (2012b) for

252 details. With that, relative sensitivities $S_{x_{i}}$ are unity, i.e. $S_{x_{i}}=1$, for all input variables and

253 regression models (Slob 1994) and the uncertainty of model output exclusively depends on

254 the variances of input variables and regression models. Considered in this analysis are

255 pesticide-specific uncertainty factors for regression models and data for dissipation half-lives

256 in crops (Fantke et al. 2014) representing the most uncertain variable in determining pesticide

257 mass in crop harvest (Fantke et al. 2012b, Juraske et al. 2008), degradation half-lives in soil as

258 proxy for soil residence times taken from the Pesticide Properties Database (Footprint 2014)

259 or U.S. EPISuite (US-EPA 2012), crop-specific residue regression models for different

260 harvest fraction ranges (Fantke et al. 2012b), post-harvest food processing (Keikotlhaile et al.

261 2010, Liang et al. 2014), fractions of applied pesticides lost to air and soil (DEFRA 2006),

262 cancer and non-cancer dose-response information and severity factors (Huijbregts et al. 2005).

$263 \mathrm{GSD}_{x_{i}}^{2}$ for all considered input variables and regression models are summarized in the SI,

264 Section S-2. Since the harvest fraction regression model for each crop $c$ in Eq. 6 involves an 
265 exponent of the complex form $\mathrm{hF}_{x, c, t}=10^{\left(\alpha_{x, c}^{*}+\beta_{x, c} \times k_{x, c} \times t_{x}\right)}$, Eq. 7 was first applied within its

266 domain of application to determine the $95 \%$ confidence interval of

$267 \log \left(\mathrm{hF}_{x, c, t}\right)=\alpha_{x, c}^{*}+\beta_{x, c} \times k_{x, c} \times t_{x}$. The two-sided limits forming the confidence interval are

268 then calculated as $\mathrm{hF}_{x, t}=\sum_{c} 10^{\log \left(\mathrm{hF}_{x, c t}\right)}$, yielding separate upper and lower $95 \%$ confidence

269 interval limits at the level of harvest fractions, intake fractions and characterization factors.

\section{$271 \quad 3 \quad$ Results}

2723.1 Intake fractions from pesticides applied to food crops

273 The variability of intake fractions for 875 pesticides applied to six crops is shown in

$274<$ Figure 1, contrasting the contributions of the fractions of applied pesticide reaching the

275 agricultural food crops as residues and of the fractions reaching air and soil as emissions

276 during and after application, of which the latter two are summed over all contributing

277 exposure pathways. Intake fractions aggregated over crop residues and fractions lost to air and

278 soil vary between 4 (tomato) and 6 (wheat, paddy rice, lettuce) orders of magnitude across

279 pesticides applied to the same crop, demonstrating the importance of substance properties on

280 crop residue dynamics. Aggregated intake fractions for the same pesticide applied to different

281 crops vary between a factor 2.6 for herbicide florasulam and more than 5 orders of magnitude

282 for 1-naphthol, a metabolite of insecticide carbaryl, demonstrating that the influences of crop

283 characteristics and pesticide application times on crop residue dynamics are as important as

284 the influence of substance properties. Individual intake fractions are provided for each of the

285875 pesticides and six crops in the SI, Section S-3.

287 <Figure 1> 
Highest aggregated intake fractions are found in lettuce and tomato with median values across pesticides of 0.035 and $0.013 \mathrm{~kg}_{\text {intake }} \mathrm{kg}_{\text {applied }}^{-1}$, respectively, which is mostly due to very short averaged application times before harvest for insecticides and fungicides. In contrast, lowest aggregated intake fractions are found in potato with a median of $6 \times 10^{-6}$

$293 \mathrm{~kg}_{\text {intake }} \mathrm{kg}_{\text {applied }}^{-1}$. The highest intake fractions for individual pesticide-crop combinations are 294 found for fungicides cyproconazole and fuberidazole on lettuce yielding each 0.27 295 $\mathrm{kg}_{\text {intake }} \mathrm{kg}_{\text {applied }}^{-1}$. Exposure from intake of crop residues is the main contributor to aggregated 296 intake fractions for 88 to $97 \%$ of all pesticides in wheat, paddy rice, tomato, apple, and 297 lettuce. For these crops, exposure from fractions lost to air and soil is the main contributor to 298 aggregated intake fractions for only 1.3 to $7 \%$ of all pesticides (<Figure $\mathbf{1}$, grey vs. white 299 boxes). Potato is an exception, where exposure from fractions lost to air and soil is generally exceeding exposure from residues in treated crop and where the fraction lost to soil is the main contributor to aggregated intake fractions for $60 \%$ of the pesticides. For $35 \%$ of

302 pesticides, the main contribution is from fractions lost to air and only $5 \%$ of all pesticides 303 show main contribution from crop residues in potato.

304 The largest variability is shown for intake fractions associated with crop residues, which 305 is mainly due to differences in application times between crops and between herbicides and 306 other pesticides applied to the same crop. As an example, intake fractions associated with 307 pesticides applied to apple trees show a variability of 6 orders of magnitude due to the large 308 difference in average application times of 150 days (herbicides) and 14 days (non-herbicides) 309 before crop harvest. Lower intake fraction ranges for all crops are associated with herbicides that are on average applied much longer before harvest than other pesticides, thereby allowing

311 removal processes to limit crop residues at harvest time. In contrast, fungicides and

312 insecticides are typically applied at later crop stages (sometimes even quickly before harvest) 313 and therefore cover the upper range of crop residue-related intake fractions. Aggregated 
314 intake fractions for the individual pesticides and crops per $\mathrm{kg}$ applied are given in the SI,

315 Section S-3, along with their $95 \%$ confidence intervals.

3.2 Human toxicological characterization factors for pesticides

Combining human intake fractions per mass of pesticide applied to different crops with toxicological effect information yields characterization factors shown in $<$ Figure 2 . Whereas intake fractions could be derived for all 875 pesticides, cancer and non-cancer effect data are only available for a subset of 177 pesticides (20\%) and 395 pesticides (45\%), respectively. Hence, characterization factors are provided in the SI for a total of 465 pesticides associated with each of the six considered crops representing $53 \%$ of all pesticides included in this study.

$<$ Figure 2>

Characterization factors for cancer-related effects typically show a lower variability than factors for non-cancer effects, which is linked to the fewer dose-response data available for cancer; hence, we provide carcinogenicity-related characterization factors only for a limited 330 number of pesticides. In contrast, characterization factors for cancer effects seem to be more evenly distributed over the variability range than factors for non-cancer effects, most visible for lettuce and least visible for tomato (white boxes in <Figure 2). This effect is linked to the influence of the variability of crop residue-related intake fractions (dominating overall human

334 intake for all crops but potato) shown in <Figure 1, where $50 \%$ of the data around the mean value for lettuce spread over more than 2 orders of magnitude, while $50 \%$ of data around the mean for tomato only differ by a factor 4.5. In line with this, the variability of characterization factors combining cancer and non-cancer effects (grey boxes in <Figure 2) is influenced by 338 the crop-specific variability of all contributing intake fractions (related to crop residues, air and soil fractions) and the variability of effect factors weighted by the number of contributing 
data points (less for cancer, more for non-cancer effects). The highest variability of

341 characterization factors is seen for lettuce with more than 9 orders of magnitude between

342 lowest and highest factors of $4.4 \times 10^{-9} \mathrm{DALY} \mathrm{kg}_{\text {applied }}^{-1}$ for ethanol and 9.3 DALY kg $\mathrm{applied}^{-1}$

343 (attributable to the population-based cumulative risk of 3.4 non-cancer incidences $\mathrm{kg}_{\text {applied }}^{-1}$ ) for

344 phenylmercuric acetate, respectively. Tomato shows the lowest variability in characterization

345 factors of about 7 orders of magnitude ranging from $5.3 \times 10^{-8} \mathrm{DALY} \mathrm{kg}_{\text {applied }}^{-1}$ for florasulam

346 and 1.5 DALY kg applied (attributable to $1.6 \times 10^{-3}$ cancer incidences and 3.9 non-cancer

347 incidences $\mathrm{kg}_{\text {applied }}^{-1}$ ) for 2,4/2,6-toluene diisocyanate. Median values of characterization

348 factors in aboveground crops across pesticides vary by less than a factor of 2 in descending

349 order as lettuce $>$ tomato $>$ apple $>$ paddy rice $>$ wheat, whereas the median value for potato

350 is 5 orders of magnitude lower. Characterization factors at midpoint level (cancer and non-

351 cancer incidences $\mathrm{kg}_{\text {applied }}^{-1}$ ) and endpoint level (DALY $\mathrm{kg}_{\text {applied }}^{-1}$ given separately for cancer and

352 non-cancer effects as well as aggregated over both) are given for all pesticide-crop

353 combinations in the SI, Section S-3, including their 95\% confidence intervals.

354 In Fig, we demonstrate along a realistic example how we arrived at characterization

355 factors given in <Figure 2 and given per pesticide in SI (Section S-3), and how to apply

356 human intake fractions and characterization factors in the context of LCA. We used as

357 example pesticides tebuconazole and pyraclostrobin, both currently authorized e.g. in the

358 European Union (European Commission 2011), and registered e.g. in Germany for use

359 against leaf rust (Puccinia recondita) on wheat (BVL 2015).

361 <Figure 3> 
3.3 Uncertainty in characterization modeling of pesticides

Uncertainty expressed as $95 \%$ confidence interval (CI) ranges is shown in Figure 4 for harvest fractions of 5250 pesticide-crop combinations. Confidence intervals are generally smallest for potato (median ratio of $97.5 \%$-ile and $2.5 \%$-ile CI limits of a factor 20 ), followed by tomato and apple (median 95\% CI limit ratios of a factor 120 and 140, respectively), and are largest for lettuce and wheat (median 95\% CI limit ratios of a factor 570 and 2680, respectively). The high end uncertainty for wheat is partly attributable to the long assumed time between application and crop harvest for herbicides (see SI, Section S-1). The much lower harvest fraction uncertainty ranges for pesticides applied to potato compared with applications to other crops is related to lacking uncertainty data for residence times in soil and, hence, does not indicate higher quality of regression models for potato.

Accuracy is in general higher in the range of high intake fractions and for the upper $97.5^{\text {th }}$ percentile, whereas uncertainty grows with decreasing intake fractions as well as for the $2.5^{\text {th }}$ percentile lower uncertainty limit. Accounting for improved estimates of half-lives is crops from Fantke et al. (2014) compared to earlier correlations from e.g. Juraske et al. (2008) has led to substantial changes and improvement in the accuracy of estimated harvest fractions (see SI, Figure S1). The range of pesticide half-lives in crops is now much narrower than the earlier estimates leading to a significant reduction in the variability between harvest fractions.

In all crops except potato, half-lives in/on crops along with time between pesticide application and crop harvest are the main contributor to crop residue dynamics. In case of potato the overall residence time in soil is the most influential factor that accounts for the various removal processes in the heterogeneous soil layer, before pesticides can enter the tuber via root uptake mechanisms (Juraske et al. 2011). Applying relatively large uncertainty 
to the crop-specific residues regression models compared with a relatively low generic uncertainty to soil degradation as proxy for overall soil residence time (most important for potato) yields generally lower uncertainty ranges of harvest fractions for potato than for all other crops. Harvest fractions for all pesticide-crop combinations are given in the SI, Section S-3, along with their $95 \%$ confidence intervals.

Despite uncertainty related to harvest fractions, uncertainty in subsequent human intake fractions (not shown) is scaled for each crop by the uncertainty associated with food processing factors, which were applied for each crop assuming a specific food processing step (see SI, Section S-1), but which were available as specific factors only for very few of the considered pesticides. Uncertainty from food processing, however, contributes on average only with $5.8 \%$ to intake fraction uncertainty across crops.

The highest share of characterization factor uncertainty with an average contribution of $70 \%$ is attributable to dose-response information, especially for extrapolated non-cancer effects. This is inherently limited by the availability of toxicity data for both risk assessment and LCA. Effective doses causing an effect in $50 \%$ of the exposed population have therefore mainly been extrapolated from toxicological studies with animals for which the specific health endpoints are mostly unknown, but derived from no-observed effect levels (NOEL). Using NOEL as starting point for estimating no-effect exposures leads to higher uncertainties (e.g. Landis \& Chapman 2011) due to the large uncertainty around dose-response

409 information. Since this type of effect information has been used in USEtox, we relied on the 410 same data to ensure comparability across impact pathways and chemicals. 
Figure 5 shows human health endpoint characterization factors for 465 pesticides with

415 available effect information applied to 6 crops along with pesticide-specific uncertainty

416 ranges that vary up to 9 orders of magnitude across pesticides applied to the same crop.

417 Regarding the level of uncertainty and since uncertainty in the upper range of characterization

418 factors is lower, Figure 5 is especially useful to provide an upper limit on the human health

419 characterization factors and to identify with a food crop-related LCA study which pesticide(s)

420 may provide a significant contribution compared to other life cycle impacts on human health

421 associated with e.g. respiratory effects from exposure to fine particulate matter.

\section{Discussion}

4.1 Influences on intake fraction variability

Our results show that pesticide properties and crop characteristics are both strongly contributing to the variability of crop residues, fractions lost to air and soil, and subsequent human intake fractions of pesticides applied to agricultural food crops. We acknowledge that site characteristics, such as local soil and climate conditions during crop growth, and scenario characteristics, such as food processing and human consumption pattern might additionally contribute to the variability of our results, although to a lesser extent. The importance of crop characteristics, such as water content, growth, and leaf area index evolution, for crop residue dynamics is well in line with other studies demonstrating the strong influence of the choice of crop data on chemical distribution kinetics in crops (Trapp 2015) and on plant uptake

434 dynamics from soil (Sun et al. 2014). Most importantly, the influence of all factors contributing to the variability of intake fractions from exposure to crop residues - the predominant component in the aggregated intake fractions from pesticide application to all considered crops except potato - is mostly associated with uncertainty of pesticide dissipation half-lives in crops. Uncertainty is additionally growing with increasing time between 
increasing with longer time to harvest allowing different uncertain model input variables to

441 develop a significant influence on model output. However, with increasing time to harvest,

442 intake fractions are typically lower, which makes the larger uncertainty less relevant than the

443 (comparatively) lower uncertainty in the main range of interest, i.e. intake fractions $\geq 10^{-5}$

$444 \mathrm{~kg}_{\text {intake }} \mathrm{kg}_{\text {applied }}^{-1}$ This effect is shown in Figure 4 for harvest fractions as main driver of the

445 magnitude of intake fractions. Uncertainty around fractions lost to air and soil along with

446 associated intake fractions for emissions to air and soil are likely being underestimated in our

447 study, since generic values for fractions lost and generic uncertainty for intake fractions have

448 been used lacking more detailed data. This will not influence the general trends of our results,

449 since these indirect contributions are low for most crops. Incorporating more realistic

450 uncertainty values would nevertheless increase the variability of aggregated intake fractions

451 for potato (with increasing time to harvest), where fractions lost to air and soil are dominating

452 aggregated intake fractions for most pesticides (see <Figure 1).

453 Overall, we reduced intake fraction variability between 1 and 9 orders of magnitude for

454 pesticides applied to potato and apple, respectively, compared with estimates reported by

455 Fantke et al. (2011b) for 121 pesticides (accounting for only $14 \%$ of the number of pesticides

456 included in the present study). This reduction of variability in intake fractions is mainly

457 attributable to improved dissipation data in crops. Overall, the uncertainty around intake

458 fractions that is mainly driven by uncertainty in crop residues (Figure 4), is generally limited

459 compared to uncertainty of characterization factors (Figure 5) that is strongly increased and

460 dominated by uncertainty of (mainly non-cancer) dose-response information.

4.2 Accounting for realistic pesticide application

According to current national and international pesticide legislation we acknowledge that

464 not all pesticides are allowed for use on all crops. In fact, there are many pesticides that are

465 registered in some countries but banned for use in agriculture in other countries. Atrazine for 
example is a herbicide with endocrine disrupting properties (Hayes et al. 2011) that is one of

467 the most widely used agricultural pesticides registered for use in the U.S. primarily on maize and sugarcane (US-EPA 2006), whereas its authorization in EU member states is withdrawn since 2004 (European Commission 2004). Given the heterogeneity in pesticide regulation between countries, we emphasize the need to verify the authorization status of all pesticides

471 when applying our data. This is especially relevant when using our results for purposes of 472 pesticide substitution and similar comparative assessments, where comparing two pesticides 473 of which only one is registered for use on a specific crop could be misleading, if the unregistered pesticide shows lower intake fractions or characterization factors. Furthermore, we acknowledge that application times (days before crop harvest) are pesticide-crop combination-specific as a function of distribution dynamics in each crop-specific environment. In this study, we used application times before harvest that are averaged separately for herbicides and other pesticides to represent "typical" application times as best estimates for LCA that can also be applied to pesticides currently not included in our assessment. However, the uncertainty related to pesticide-specific application times before 481 harvest for each crop (and country) is not included in our study and varies strongly between 482 pesticides.

\subsection{Data limitations and applicability in LCA studies}

Our study shows several limitations. Experimental data for the most sensitive input variable, that is dissipation half-lives in crops, are only available for 311 out of 875 pesticides

487 (35\%). To account for the related uncertainty, we considered the higher uncertainty of the regression model to estimate crop dissipation to all pesticides, where experimental data were missing. The new correlations on half-lives have however substantially improved the accuracy of estimating related crop residues. Residence times in soil are the output of a 
solved under the assumption of steady-state conditions with continuous emission input (Rosenbaum et al. 2008). Soil residence times are thereby influenced by a wide range of environmental characteristics including crop-related aspects and pesticide properties, of which degradation in soil plays an important role (Dubus et al. 2003). Lacking uncertainty data for soil residence times we applied uncertainty associated with soil degradation as proxy. We thereby acknowledge that we might underestimate the overall uncertainty specifically for potato, where soil residence time is driving the magnitude of crop residues and subsequent human intake. Whenever possible, soil degradation data are based on measurements aggregated in Footprint (2014) and only complemented by estimated data from the US-EPA (2012) when no experimental data were available. Differences in soil degradation data sources lead to differences in associated uncertainty, which were not considered in our study. We thereby acknowledge that data estimated from pesticide physicochemical properties may exceed measured field soil degradation half-lives by up to more than two orders of magnitude as can be seen when comparing e.g. tralomethrin or 8-quinolinol. These differences are becoming relevant in regulatory contexts, but are not as important in pure comparative assessments like LCA, where we are not bound to absolute thresholds for e.g. persistence in soil. Another limitation in our study is the use of generic fractions lost to air during and after pesticide application and associated uncertainty estimates. Further research is required to estimate these fractions more accurately in the context of LCA (Rosenbaum et al. 2015). However, for the majority of pesticide-crop combinations, this will not substantially influence related intake, since fractions lost to air are mostly not dominating intake fractions. Finally, we apply pesticide-specific data and averaged uncertainty factors for human health doseresponse slope factors that are extrapolated from distinct exposed animal populations, exposure durations and routes and that are aggregated over a wide range of health endpoints (particularly for non-cancer effects). The difficulty to extrapolate effect factors from such inherently heterogeneous data leads to a significant contribution of dose-response information 
to overall uncertainty in characterization factors, which has already been acknowledged in

519 previous studies (Huijbregts et al. 2005, Rosenbaum et al. 2008). While the quality of data underlying human toxicological effect factors needs to be improved accordingly, the variability of characterization factors across all pesticide-crop combinations spanning more than 9 orders of magnitude shows that relative to variability, overall uncertainty is not higher for toxicity-related impacts than for other impact categories.

Despite abovementioned limitations, our study contributes to significantly advancing the assessment of human health-related impacts from exposure to pesticides in LCA by including the predominant exposure pathway (i.e. intake of crop residues) and by improving the quality of the most uncertain input data for estimating pesticides in crop harvest (i.e. dissipation data in crops; see SI, Figure S1). Since our characterization factors are based on mass applied,

529 LCA practitioners can and need to directly combine our results with pesticide application data as demonstrated in Fig. Whenever such data are not at hand, recommended application dosages as provided in The Pesticide Manual (Tomlin 2012) or on pesticide product labels

532 can be applied as proxy.

\section{Conclusions}

We provide an operational framework for including human toxicity-related effects from exposure to pesticides via consumption of treated food crops into LCIA and provide for the

537 first time uncertainty ranges around harvest fractions, intake fractions and characterization

538 factors that are specific for each pesticide and crop. Results demonstrate that impacts of

539 pesticides in terms of human toxicity are largely underestimated when ignoring exposure to

540 residues in harvested and subsequently consumed crop components. For ready use in LCA

541 studies, we present pesticide-crop combination-specific characterization factors normalized to

542 pesticide mass applied and provide default data for application times and loss due to post-

543 harvest food processing. Uncertainty needs to be considered when comparing results between 
different pesticides or with other chemicals to properly interpret ranking and maximum

545 contributions, as it has been shown that pesticides with lower median characterization factors

546 can be as important as pesticides with higher median characterization factors when

547 considering the pesticide-specific uncertainty ranges. Improving dissipation half-lives in crops

548 derived from experimental data has been essential in limiting uncertainties on harvest

549 fractions. Further studies are required to better estimate fractions lost to air and soil during

550 and after pesticide application and to reduce the inherent uncertainty in non-cancer toxicity

551 effect information. When using our data, we emphasize the need to consult current pesticide

552 regulation to allow for realistic scenarios where each pesticide is registered for use on certain

553 crops only, which varies between countries.

\section{Acknowledgements}

This work was financially supported by the Marie Curie project Quan-Tox (grant agreement no. 631910) funded by the European Commission under the Seventh Framework

Programme.

\section{References}

Andersson K (2000) LCA of food products and production systems. Int. J. Life Cycle Assess.

BASF (2012) HEADLINE® EC Fungicide Product Label, BASF Canada Inc., Mississauga, Ontario

Bayer (2014) Pflanzenschutz-Empfehlungen 2014, Bayer AG CropScience, Zollikofen, Switzerland

BVL (2015) Online data base of plant protection products. Bundesamt für Verbraucherschutz und Lebensmittelsicherheit, Berlin. <https://apps2.bvl.bund.de/psm/jsp/> 
DEFRA (2006) Web-integrated framework for addressing uncertainty and variability in pesticide risk assessment, Department for Environment Food and Rural Affairs

Dickson-Spillmann M, Siegrist M, Keller C, Wormuth M (2009) Phthalate exposure through food and consumers' risk perception of chemicals in food. Risk Anal. 29:1170-1181

Dubus IG, Brown CD, Beulke S (2003) Sources of uncertainty in pesticide fate modelling. Sci. Total Environ. 317:53-72

European Commission (2004) 2004/248/EC: Commission Decision of 10 March 2004 concerning the non-inclusion of atrazine in Annex I to Council Directive 91/414/EEC and the withdrawal of authorisations for plant protection products containing this active substance, Brussels

European Commission (2006) Special Eurobarometer 238, Wave 64/1 - Risk Issues, Brussels

European Commission (2009) Regulation (EC) No 1107/2009 of the European Parliament and of the Council of 21 October 2009 concerning the placing of plant protection products on the market and repealing Council Directives 79/117/EEC and 91/414/EEC, Brussels

European Commission (2010) International Reference Life Cycle Data System (ILCD) Handbook : Framework and requirements for LCIA models and indicators, First Edition, Brussels

European Commission (2011) Commission Implementing Regulation (EU) No 540/2011 of 25 May 2011 implementing Regulation (EC) No 1107/2009 of the European Parliament and of the Council as regards the list of approved active substances, Brussels

Fantke P, Charles R, de Alencastro LF, Friedrich R, Jolliet O (2011a) Plant uptake of pesticides and human health: Dynamic modeling of residues in wheat and ingestion intake. Chemosphere 85:1639-1647

Fantke P, Juraske R, Antón A, Friedrich R, Jolliet O (2011b) Dynamic multicrop model to characterize impacts of pesticides in food. Environ. Sci. Technol. 45:8842-8849

Fantke P, Friedrich R, Jolliet O (2012a) Health impact and damage cost assessment of pesticides in Europe. Environ. Int. 49:9-17

Fantke P, Wieland P, Juraske R, Shaddick G, Sevigné E, Friedrich R, Jolliet O (2012b) Parameterization models for pesticide exposure via crop consumption. Environ. Sci. Technol. 46:12864-12872

Fantke P, Juraske R (2013) Variability of pesticide dissipation half-lives in plants. Environ. Sci. Technol. 47:3548-3562

Fantke P, Wieland P, Wannaz C, Friedrich R, Jolliet O (2013) Dynamics of pesticide uptake into plants: From system functioning to parsimonious modeling. Environ. Modell. Softw. 40:316-324

Fantke P, Gillespie B, Juraske R, Jolliet O (2014) Estimating half-lives for pesticide dissipation from plants. Environ. Sci. Technol. 48:8588-8602 
FAO (2003) Development of a Framework for Good Agricultural Practices. COAG/2003/6,

Footprint (2014) The Pesticide Properties Database (PPDB 2.0) of the Footprint Project. $<$ http://sitem.herts.ac.uk/aeru/ppdb>

Freeman NCG (2011) Exposure Science: Ingestion. In: Nriagu JO (Editor), Encyclopedia of

Ganzelmeier H, Rautmann D, Spagenberg R, Streloke M, Hermann M, Wenzelburger HJ, Walter HF (1995) Studies on the spray drift of plant protection products, Blackwell, Berlin

Hayes TB, Anderson LL, Beasley VR, de Solla SR, Iguchi T et al. (2011) Demasculinization and feminization of male gonads by atrazine: Consistent effects across vertebrate classes. J. Steroid. Biochem. 127:64-73

Huijbregts MAJ, Rombouts LJA, Ragas AMJ, van de Meent D (2005) Human-toxicological effect and damage factors of carcinogenic and noncarcinogenic chemicals for life cycle impact assessment. Integr. Environ. Assess. Manage. 1:181-244

Itoiz ES, Fantke P, Juraske R, Kounina A, Antón Vallejo A (2012) Deposition and residues of azoxystrobin and imidacloprid on greenhouse lettuce with implications for human consumption. Chemosphere 89:1034-1041

Juraske R, Antón A, Castells F (2008) Estimating half-lives of pesticides in/on vegetation for use in multimedia fate and exposure models. Chemosphere 70:1748-1755

Juraske R, Sanjuán N (2011) Life cycle toxicity assessment of pesticides used in integrated and organic production of oranges in the Comunidad Valenciana, Spain. Chemosphere 82:956-962

Juraske R, Vivas CSM, Velsquez AE, Santos GG, Moreno MBB, Gomez JD, Binder CR, Hellweg S, Dallos JAG (2011) Pesticide uptake in potatoes: Model and field experiments. Environ. Sci. Technol. 45:651-657

Juraske R, Fantke P, Romero Ramírez AC, González A (2012) Pesticide residue dynamics in passion fruits: Comparing field trial and modeling results. Chemosphere 89:850-855

Kaushik G, Satya S, Naik SN (2009) Food processing a tool to pesticide residue dissipation A review. Food Res. Int. 42:26-40

Keikotlhaile BM, Spanoghe P, Steurbaut W (2010) Effects of food processing on pesticide residues in fruits and vegetables: A meta-analysis approach. Food Chem. Toxicol. 48:1-6

Kramer HJ, van den Ham WA, Slob W, Pieters MN (1996) Conversion factors estimating indicative chronic no-observed-adverse-effect levels from short-term toxicity data. B. Environ. Contam. Tox. 23:249-255

Landis WG, Chapman PM (2011) Well past time to stop using NOELs and LOELs. Integr. Environ. Assess. Manage. 7:vi-viii 
Liang Y, Liu Y, Ding Y, Liu XJ (2014) Meta-analysis of food processing on pesticide residues in fruits. Food Addit. Contam. 31:1568-1573

Lippmann M (2009) Environmental Toxicants: Human Exposures and Their Health Effects, 3rd Ed. Wiley and Sons, Hoboken, New Jersey

Lu C, Barr DB, Pearson MA, Waller LA (2008) Dietary intake and its contribution to longitudinal organophosphorus pesticide exposure in urban/suburban children. Environ. Health Persp. 116:537-542

McKinlay R, Plant JA, Bell JNB, Voulvoulis N (2008) Endocrine disrupting pesticides: Implications for risk assessment. Environ. Int. 34:168-183

Muncke J (2009) Exposure to endocrine disrupting compounds via the food chain: Is packaging a relevant source? Sci. Total Environ. 407:4549-4559

Perrin A, Basset-Mens C, Gabrielle B (2014) Life cycle assessment of vegetable products: A review focusing on cropping systems diversity and the estimation of field emissions. Int. J. Life Cycle Assess. 19:1247-1263

Pretty JN (2005) The Pesticide Detox: Towards a More Sustainable Agriculture. Earthscan, London, UK

Rautmann D, Streloke M, Winkler R (2001) New basic drift values in the authorisation procedure for plant protection products. Biologische Bundesanstalt für Land- und Forstwirtschaft, Berlin, Braunschweig

Rein A, Legind CN, Trapp S (2011) New concepts for dynamic plant uptake models. SAR QSAR Environ. Res. 22:191-215

Rosenbaum RK, Bachmann TM, Gold LS, Huijbregts MAJ, Jolliet O, Juraske R, Koehler A, Larsen HF, MacLeod M, Margni MD, McKone TE, Payet J, Schuhmacher M, van de Meent D, Hauschild MZ (2008) USEtox - The UNEP-SETAC toxicity model: Recommended characterisation factors for human toxicity and freshwater ecotoxicity in life cycle impact assessment. Int. J. Life Cycle Assess. 13:532-546

Rosenbaum RK, Anton A, Bengoa X, Bjørn A, Brain R et al. (2015) The Glasgow consensus on the delineation between pesticide emission inventory and impact assessment for LCA. Int. J. Life Cycle Assess.:doi:10.1007/s11367-015-0871-1

Roy P, Nei D, Orikasa T, Xu Q, Okadome H, Nakamura N, Shiina T (2009) A review of life cycle assessment (LCA) on some food products. J. Food Eng. 90:1-10

Schau EM, Fet AM (2008) LCA studies of food products as background for environmental product declarations. Int. J. Life Cycle Assess. 13:255-264

Slob W (1994) Uncertainty analysis in multiplicative models. Risk Anal. 14:571-576

Slovic P (2010) Perceptions of Pesticides as Risks to Human Health. In: Krieger R (Editor), Hayes' Handbook of Pesticide Toxicology. Third Edition. Academic Press, London, UK, pp. 1381-1391 
Sun F, Kolvenbach BA, Nastold P, Jiang B, Ji R, Corvini PF-X (2014) Degradation and metabolism of tetrabromobisphenol A (TBBPA) in submerged soil and soil-plant systems. Environ. Sci. Technol.:doi:10.1021/es503383h

Tittlemier SA, Pepper K, Seymour C, Moisey J, Bronson R, Cao X-L, Dabeka RW (2007) Dietary exposure of Canadians to perfluorinated carboxylates and perfluorooctane sulfonate via consumption of meat, fish, fast foods, and food items prepared in their packaging. J. Agr. Food Chem. 55:3203-3210

Tomlin CDS (2012) The Pesticide Manual, Sixteenth Edition. BCPC Publications, British Crop Protection Council, Hampshire, UK

Trapp S (2015) Calibration of a plant uptake model with plant- and site-specific data for uptake of chlorinated organic compounds into radish. Environ. Sci. Technol. 49:395402

Udo de Haes HA, Finnveden G, Goedkoop M, Hauschild MZ, Hertwich E, Hofstetter P, Jolliet O, Klöpffer W, Krewitt W, Lindeijer E, Müller-Wenk R, Olsen S, Pennington DW, Potting J, Steen B (2002) Life-cycle impact assessment: Striving towards best practice. SETAC Press, Pensacola, Florida, USA

US-EPA (2006) Combined Decision Documents for Atrazine, United States - Environmental Protection Agency, Washington, D.C.

US-EPA (2012) Estimation Programs Interface Suite ${ }^{\mathrm{TM}}$ for Microsoft ${ }^{\circledR}$ Windows, v 4.11. United States - Environmental Protection Agency, Washington, D.C. <http://www.epa.gov/oppt/exposure/pubs/episuite.htm>

van de Zande JC, Michielsen JMGP, Stallinga H (2007) Spray drift and off-field evaluation of agrochemicals in the Netherlands, Report 149, Plant Research International B. V., Wageningen, The Netherlands 


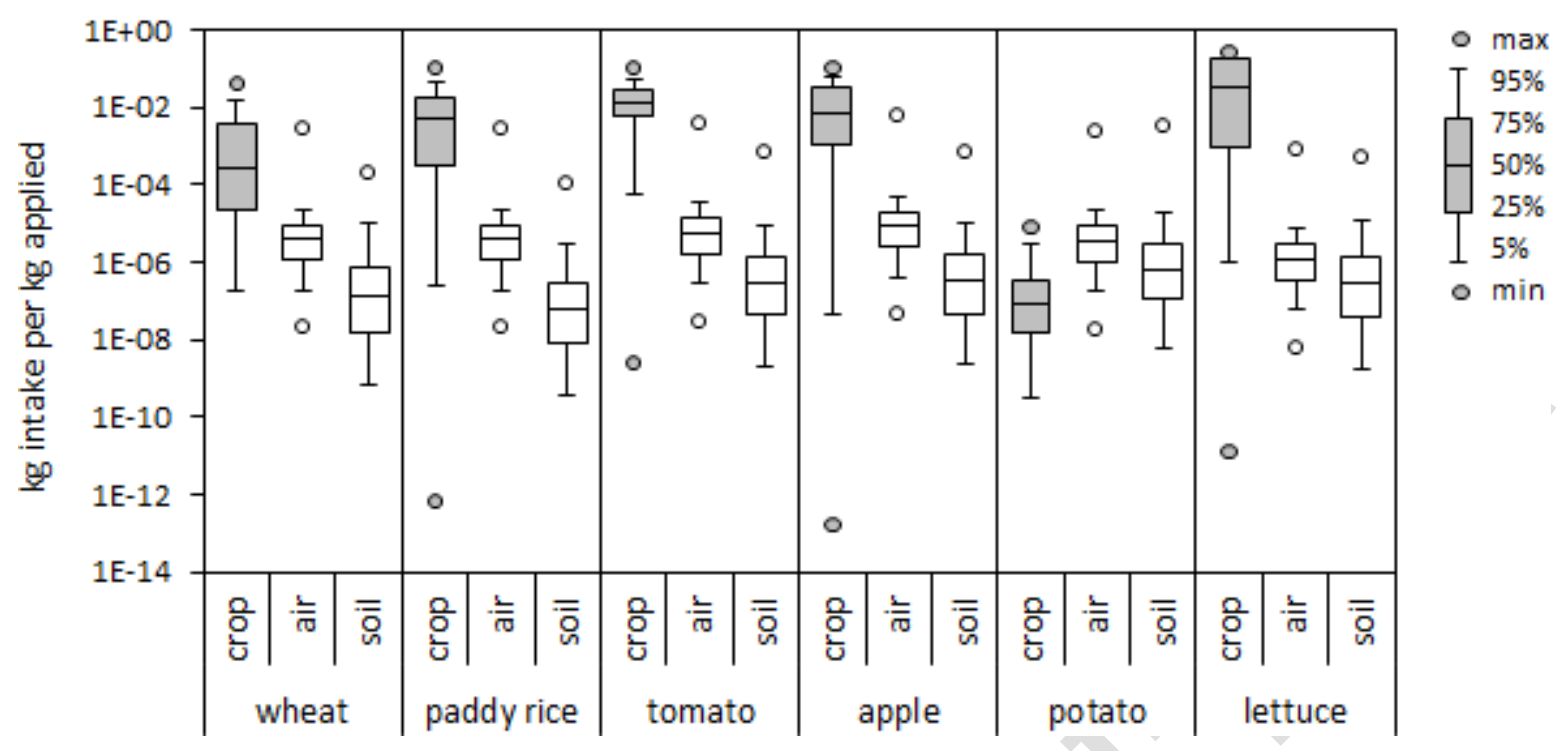

717 Figure 1 Variability of human intake fractions expressed as $\mathrm{kg}$ intake per $\mathrm{kg}$ applied pesticide

718 grouped for each crop according to fractions reaching the crop as residues (grey boxes) and

719 fractions reaching air and soil as emissions during and after application (white boxes).

720 Minimum values below $10^{-14}$ are not displayed.

721

722

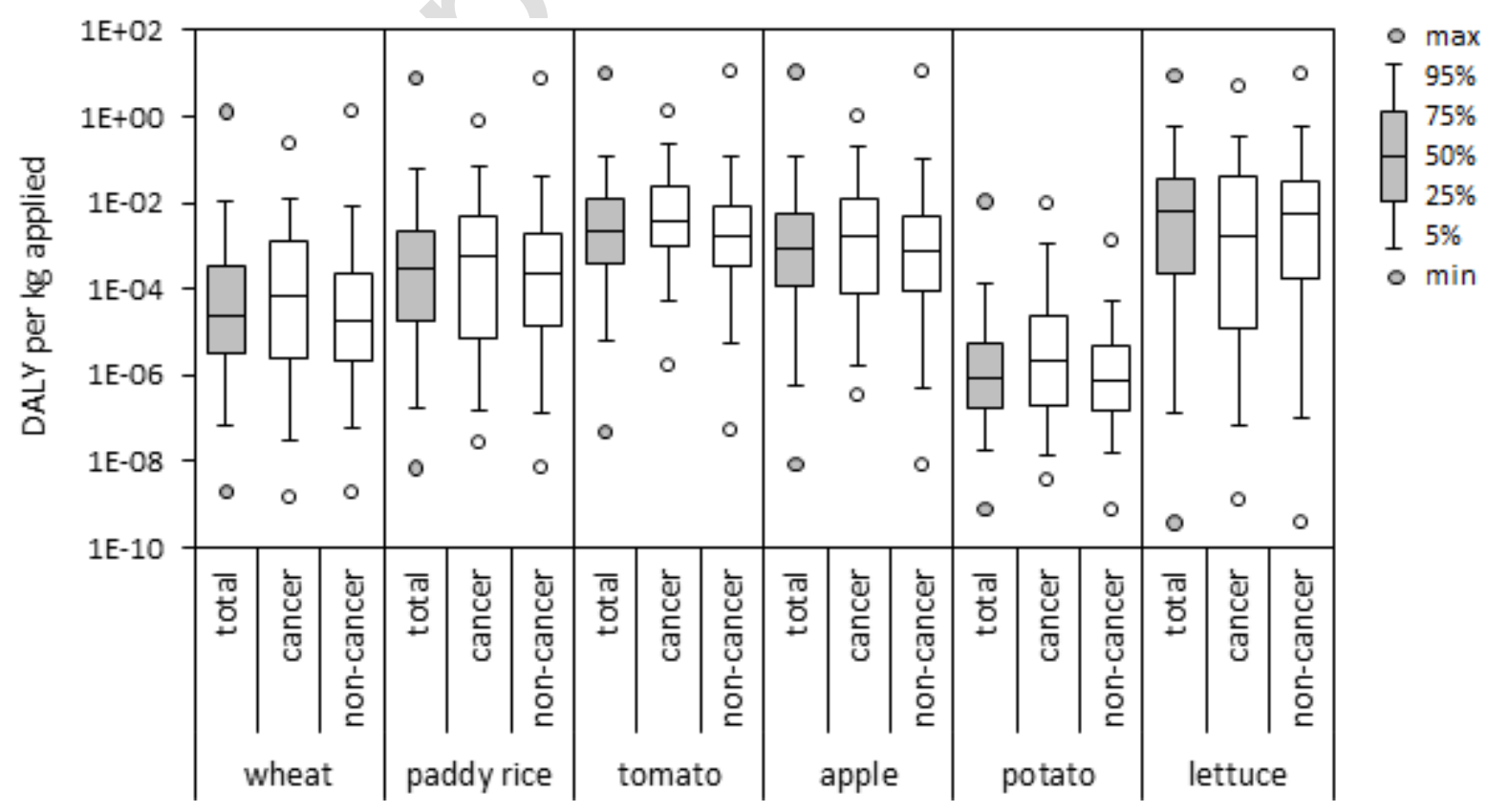


Figure 2 Variability of human toxicity endpoint characterization factors expressed as

725 disability-adjusted life years (DALY) per kg applied pesticide grouped for each crop into total aggregated effects (grey boxes), and cancer and non-cancer effects (white boxes).

727

728

729

(a) human intake $=$ mass applied per functional unit $\times$ total intake fraction

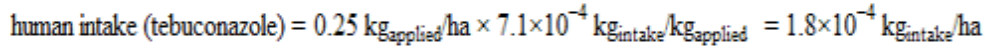

(b) characterization factor ${ }^{*}=$ total ingestion intake fraction $\times$ non-cancer dose-response for ingestion $\times$ non-cancer severity factor

$\mathrm{CF}$ (tebuconazole $)=7.1 \times 10^{-4} \mathrm{~kg}_{\text {ingested }} \mathrm{kg}_{\text {applied }} \times 0.015$ incidences non-cancer $/ \mathrm{kg}_{\text {ingested }} \times 2.7 \mathrm{DALY} /$ incidence $_{\text {non-cancer }}=2.9 \times 10^{-5} \mathrm{DALY} / \mathrm{kg}_{\text {applied }}$ $\mathrm{CF}$ (pyraclostrobin) $=2.0 \times 10^{-5} \mathrm{~kg}_{\text {ingested }} \mathrm{kg}_{\text {applied }} \times 0.042$ incidences $_{\text {non-cancer }} / \mathrm{kg}_{\text {ingested }} \times 2.7 \mathrm{DALY} /$ incidence ${ }_{\text {non-cancer }}=2.2 \times 10^{-6} \mathrm{DALY} / \mathrm{kg}_{\text {applied }}$

(c) health impact $=$ mass applied per functional unit $\times$ characterization factor

health impact (tebuconazole) $=0.25 \mathrm{~kg}_{\text {applied }}$ ha $\times 2.9 \times 10^{-5} \mathrm{DALY} / \mathrm{kg}_{\text {applied }}=7.3 \times 10^{-6} \mathrm{DALY} / \mathrm{ha}$

health impact (pyraclostrobin) $=0.125 \mathrm{~kg}_{\text {applied }}$ ha $\times 2.2 \times 10^{-6} \mathrm{DALY} / \mathrm{kg}_{\text {applied }}=2.8 \times 10^{-7} \mathrm{DALY} / \mathrm{ha}$

*In this example, we calculated the characterization factors exclusively from ingestion intake fractions (inhalation intake fractions contribute to overall intake fraction only with $0.02 \%$ for tebuconazole and $0.32 \%$ for pyraclostrobin) and non-cancer dose-response (cancer effect data were not available). Whenever inhalation intake fractions and/or cancer effects become relevant, they need to be included in the characterization factor calculations.

Figure 3 Calculation steps for deriving human intake per treated hectare (a), endpoint characterization factors (b), and health impacts per treated hectare (c) for two example fungicides applied to wheat. Tebuconazole is typically applied as $250 \mathrm{~g} / \mathrm{l} \mathrm{emulsion}$ at $1 \mathrm{l} / \mathrm{ha}$ (Bayer 2014) and pyraclostrobin is typically applied as $250 \mathrm{~g} / \mathrm{l}$ emulsion at $0.5 \mathrm{l} / \mathrm{ha}$ (BASF 2012). Intake fractions, dose-response factors and characterization factors are given in SI

(Section S-3). 

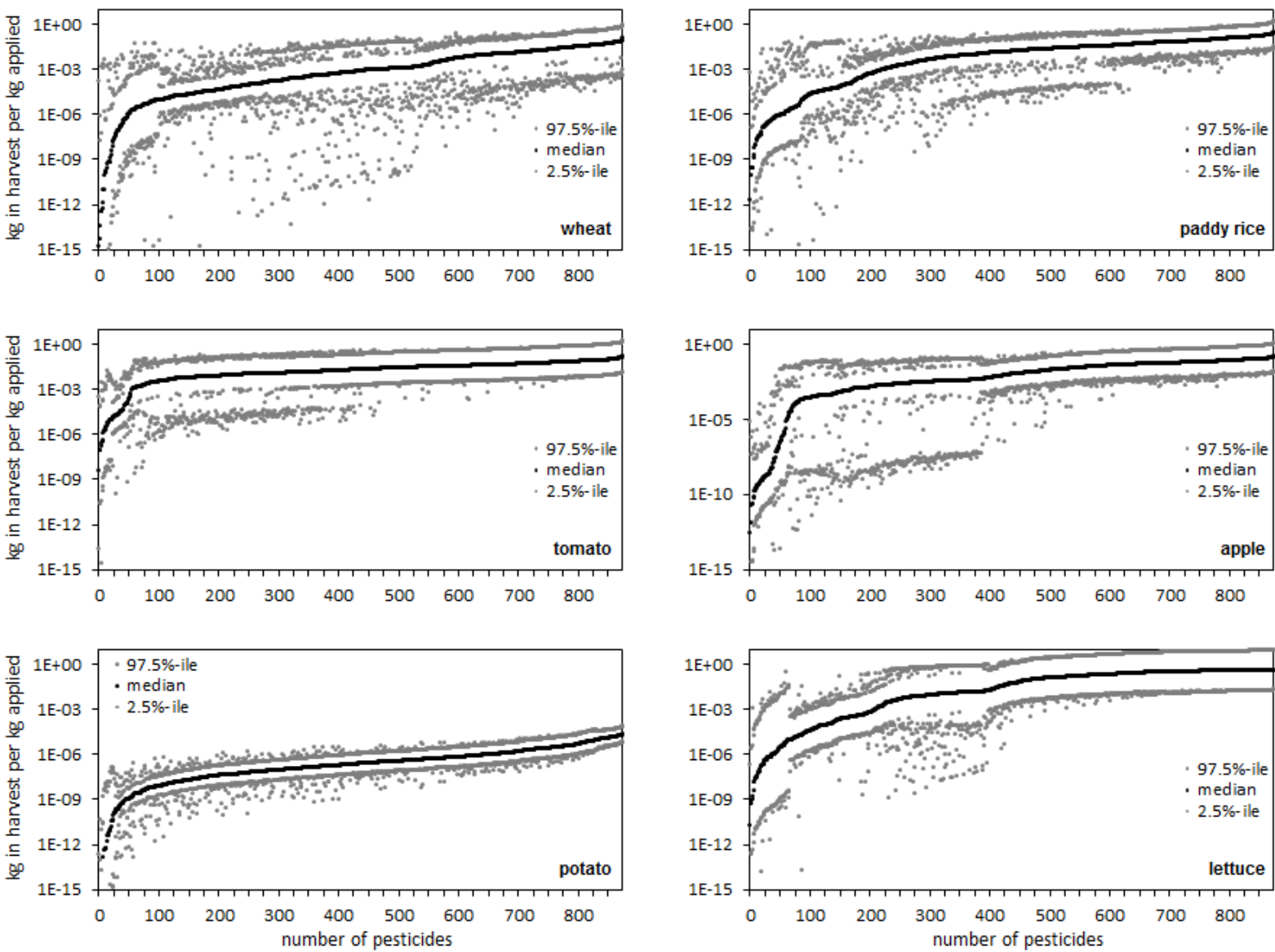

744

745 Figure 4 Uncertainty of harvest fractions for 875 pesticides and 6 crops expressed as 95\%

746 confidence interval ranges of pesticide mass in crop harvest per kg applied pesticide. 

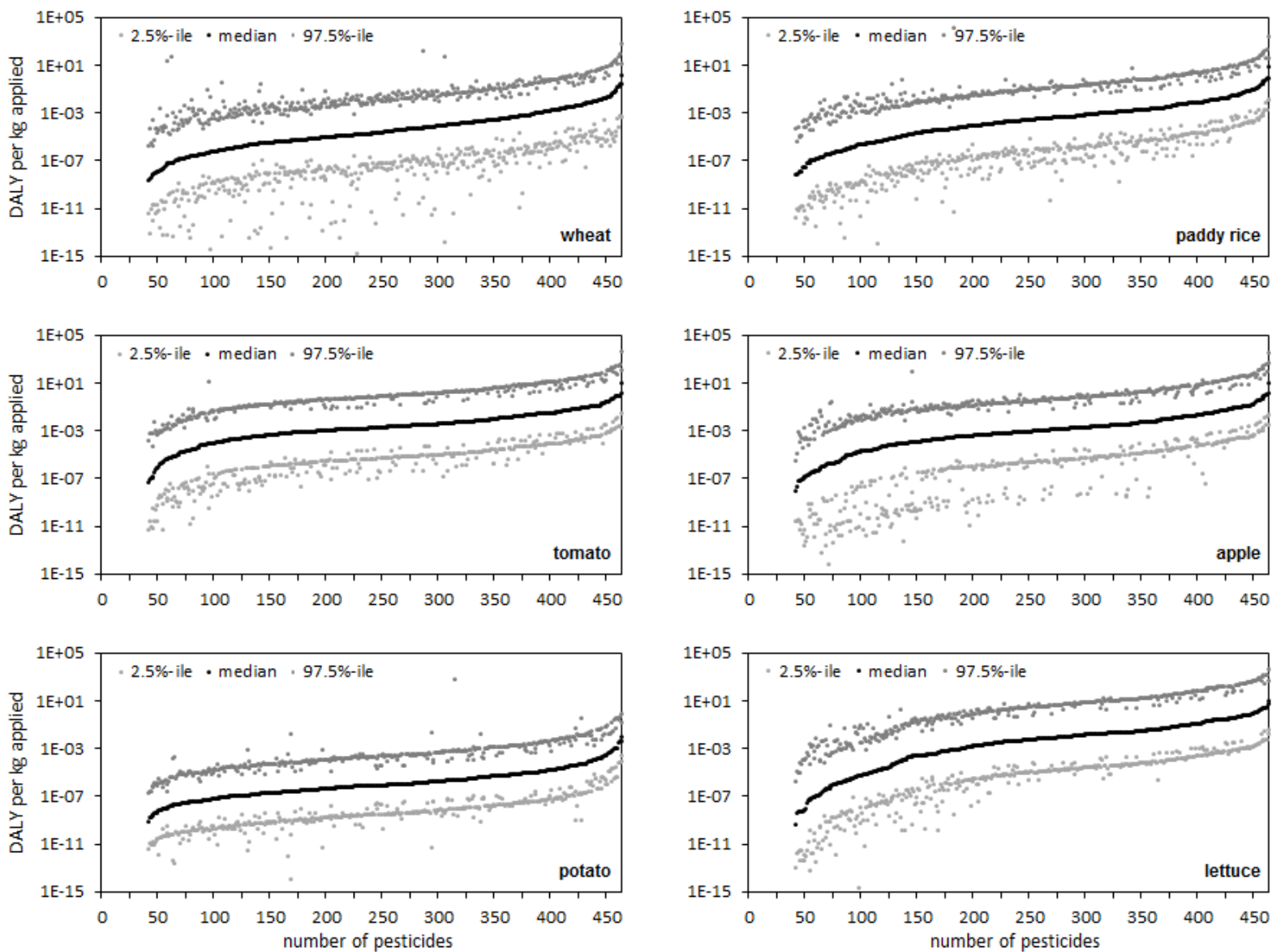

Figure 5 Uncertainty of human toxicological characterization factors at endpoint level for the

751 reduced set of 465 pesticides with available toxicity effect information and 6 crops expressed

752 as $95 \%$ confidence interval ranges of disability-adjusted life years (DALY) per kg applied

753 pesticide. 